\title{
Health, wealth, and medical expenditures among the elderly in rural Tanzania: Experiences from Nzega and Igunga districts
}

Malale Tungu ( $\sim$ malaletungu@gmail.com )

Muhimbili University of Health and Allied Sciences https://orcid.org/0000-0002-8821-493X

Phares G. Mujinja

Muhimbili University of Health and Allied Sciences

Paul J. Amani

Mzumbe University

Mughwira A. Mwangu

Muhimbili University of Health and Allied Sciences

Angwara D. Kiwara

Muhimbili University of Health and Allied Sciences

Lars Lindholm

Umea Universitet

Research

Keywords: health expenditure, wealth index, QoL, EQ-5D, elderly, Tanzania

Posted Date: September 23rd, 2021

DOI: https://doi.org/10.21203/rs.3.rs-924109/v1

License: (9) (i) This work is licensed under a Creative Commons Attribution 4.0 International License.

Read Full License 


\section{Abstract}

\section{Background}

The per capita health expenditure (HE) and share of gross domestic product (GDP) spending on elderly healthcare are expected to increase. In many developing countries like Tanzania, there is an increasing gap between health needs and the available resources for elderly healthcare, which leaves the elderly with poor health conditions, especially chronic diseases. These conditions lead to catastrophic HEs for the elderly.

\section{Objective}

This study aimed to analyse the association among health, wealth, and medical expenditure in rural residents aged 60 years and above in Tanzania.

\section{Methods}

Data were collected through a cross-sectional household survey to rural residents aged 60 years and above living in Nzega and Igunga districts. Standardised World Health Organization (WHO) Study on Global Ageing and Adult Health (SAGE) and European Quality of Life Five Dimension (EQ-5D) questionnaires were used. The quality of life (QoL) was estimated using EQ-5D weights. The wealth index was generated from principal component analysis (PCA). Two linear regression analyses (outpatient/inpatient) were performed to analyse the association among health, wealth, medical expenditure, and socio-demographic variables.

\section{Results}

This study found a negative and statistically significant association between QoL and HE, whereby HE increases with the decrease of QoL. We could not find any significant relationship between HE and social gradients. In addition, age influences HE such that as age increases, the HE for both outpatient and inpatient care also increases.

\section{Conclusion}

The health system in these districts allocate resources mainly according to needs, and social position is not important. We thus conclude that the system is fair. Health, not wealth, determines the use of medical expenditures.

\section{Introduction}

Ageing and increasing health expenditure (HE) for the elderly are two major challenges likely to influence the global health systems. This results in a sharp increase in the per capita HE and shares of gross domestic product (GDP) of many countries on healthcare (1-3). To accommodate the healthcare needs 
of the elderly, governments are challenged to put in place strategies that will improve the health service infrastructure for providing services, especially to the rural population (4). In many low- and middleincome countries (LMICs), Tanzania inclusive, there is an increasing gap between health needs and the available resources for elderly healthcare (5). Insufficient resources have made it difficult to fund and implement the needed healthcare services. Thus, priority setting is considered an important process that will enable countries to decide how best limited health resources should be allocated among competing programmes. This process occurs at all levels of healthcare systems and is one of the most important issues in healthcare management today (6).

The main idea in extra-welfarism about priority setting is to maximise population health. The best strategy to achieve this goal is certainly to allocate healthcare resources according to need, similar to views in medicine and public health (7). Importantly, extra welfarism thus rejects individual demand, i.e. ability to pay, as the mechanism to allocate resources in healthcare $(8,9)$. For the developed countries, except the US, medical care is available to all its people, regardless of income, age, or residence (5). However, things are different in many LMICs. For example, in both Tanzania and Nigeria, there are no functional social security mechanisms for elderly people, and households with elderly people are responsible for (geriatric) healthcare costs. This may increase the risk for catastrophic HEs, especially for poor households (10), or people will not use healthcare even when strongly needed.

Most of the elderly in rural areas are poor (many live on subsistence) and cannot afford escalating healthcare costs $(4,11,12)$. Therefore, elderly people are likely to be the victims of catastrophic HEs each time they are admitted to inpatient care. Catastrophic HE is defined as out-of-pocket (OOP) spending for healthcare services that exceeds $40 \%$ of the household's income (13-15).

In Tanzania, catastrophic HE among the elderly is influenced by different financing mechanisms, including cost-sharing in the healthcare services that were introduced in the early 1990s in the country. Cost-sharing becomes a burden to vulnerable groups including the elderly because of their low incomes. Although the government has put in place policies with a focus on enhancing free access to health services to the elderly population, most of the elderly still incur costs associated with medicines, diagnostic tests, and other related services upon their utilisation of healthcare services $(4,16)$. However, to qualify for an exemption, a verification process must be fulfilled before exemption identity is granted. As it is now, the provision of free services to the elderly has become another challenge to the healthcare system because there are no clear guidelines that guide the health workers at the facility and the funds that subsidise the process, i.e. the compensation of the exemption at the health facility (17). This makes effective and efficient implementation of this policy difficult (18).

The healthcare models from most developed countries can be applied by implementing policies based on taxes or public health insurance (risk pooling), which will make healthcare services free or almost free. This means that those with the highest needs should not be restricted by the cost to access healthcare services. 
The proxy for healthcare needs can be quality-adjusted-life-years (QALYs) weights. Most of the elderly suffer from one or several chronic diseases. This makes the elderly have low QALY weights and automatically have a high need for healthcare $(16,19,20)$. If the low QALY weights among the elderly are associated with a high cost for healthcare and vice versa, then there should be a fair allocation. This means that those with the highest health needs (low QALY weights) should get more health resources than those with low health needs (high QALY weights). The use of healthcare should be determined by health needs rather than by people's ability to pay (social position), which would lead to unfair allocation of resources. In many systems, the two allocation mechanisms exist in parallel. Decision-makers probably strive for healthcare distributed according to need, but in real life, they have problems achieving such a model because it requires that the rich and healthy pay a bigger share. Social position can be measured by socio-economic status (SES), which is a proxy of wealth among the elderly. SES incorporates assets, education, income, and occupation (21) and is calculated using principal component analysis (PCA). Therefore, this study aimed to investigate whether the elderly use of healthcare in Tanzania is determined by people's health or their wealth.

\section{Materials And Methods}

\section{Study setting}

This study was conducted in the Nzega and Igunga districts in the Tabora Region of western Tanzania. The districts have a total population of 901,979 (Nzega is 502,252 and Igunga is 399,727 ). About $6 \%$ of the total population of the two districts are elderly. These districts were appropriate places for our study because, among the elderly in Nzega and Igunga, 93\% and 92\%, respectively, live in rural areas (22). Nzega is divided into 37 wards with 151 villages, and Igunga is divided into 26 wards with 93 villages.

\section{Study design, sampling techniques, and sample size}

A cross-sectional household survey study was conducted to collect data from 1,899 respondents in Nzega and Igunga districts. With this total, there were 1,179 respondents in Nzega district and 720 in Igunga district. A multistage sampling method was used to select wards and thereafter villages in each district. Ward and hamlet officers guided the researchers in identifying households with elderly people. In the first stage, seven wards were selected purposively from each district based on the population size and proximity between the wards. In the second stage, 58 villages that were geographically reachable were randomly selected using a lottery method. In the third stage, a systematic sampling technique was used to identify and select 25 to 44 households with an elderly person from each village, depending on the size of the village. Consideration was given to gender balance in the selection of the respondents. The required sample size was determined to be 733 participants, based on a prevalence of the outcome of $40 \%$, a design effect of 2 , and considering a $95 \%$ confidence interval $(\mathrm{Cl})$ and $80 \%$ power (23).

\section{Measurement of health need}


To measure the health need in the study population, we used the EQ-5D instrument, which describes health status using five dimensions (mobility, self-care, usual activities, pain/discomfort, and anxiety/depression). Each dimension was divided into three levels (no problems, some problems, and severe problems). The position for each health state is on a scale of 0 and 1 , whereby 0 represents death and 1 represents perfect health. QALY weight was generated from the EQ-5D index to be used as a proxy of the health need of the elderly.

\section{Measurement of costs}

HE includes costs per visit, bed day costs, and transport costs at the health facility as per WHO[1] suggestions. HE also included registration fees, laboratory test costs, and medicine payment costs. The WHO categorises the costs according to the public, private, or faith-based organisation (FBO) health facility. This was used to construct an index with three types of costs: costs for those attending to the public, private, and charity or FBO health facility. These costs were added to the costs of the registration fee, medicines, lab tests, and transport costs to arrive at total costs.

\section{Measurement of wealth}

In addition, the wealth index was created in terms of the SES index that was constructed using PCA in a STATA programme. In constructing PCA using the STATA programme, several steps were performed. The SES index in this study comprises material ownership (assets) and occupation. The SES variable was constructed to assess the wealth index of the elderly in Nzega and Igunga by the following steps:

Step 1: Selection of variables, which were used for PCA (electricity, bicycle, motorcycle, television, radio, pressing iron, refrigerator, mobile phone, car, computer, land, cattle, income, and occupation). Step 2: Generate dummy variables. Step 3: Checking for multicollinearity (correlation of the coefficient between variables). Step 4: Checking the assumptions for PCA (Bartlett's Test and Kaiser-Meyer-Olkin [KMO] measure of sampling adequacy), which found the value of KMO > 0.5. Step 5: Thereafter, the PCA was constructed, and Eigen factors and Eigenvalues were checked. Step 6: We graphed the Eigenvalue. Step 7: We computed the component score. Step 8: Finally, the component scores were categorised into quintiles to be used in the regression as a predictor.

\section{Other variables}

Demographic variables were used as predictors (age, sex, marital status, and education level). These included sex (female/males), age (categorised into 60-69, 70-79, 80-89, and 90+), and marital status, which included those who were married (i.e., currently married and cohabiting) and non-married (i.e., widows, separated, never married, and divorced). Education included illiterate (no formal education), low (4-8 years, primary education), middle (11-14 years, secondary education), and high (university education).

\section{Data analysis}


Two linear regression analyses were performed. The multivariable regression model using simple linear regression analysis was performed to assess the association among $\mathrm{HE}$, quality of life (QoL), and SES among the elderly.

\section{Model specification}

The mutual relationship is presented in Figure 1, which shows the relationship among HE, QoL, and SES. When the elderly are ill, they need treatment, and after receiving the treatment, they may improve their health status (QoL). Also, QoL and the need for healthcare are influenced by the level of wealth/income of the individual elderly. The same applied to the vice-versa relationship, since those with a high level of wealth can probably get more and/or better healthcare, which improves their health status (24). However, our cross-sectional data do not allow us to investigate the mutual relationships. Only associations between our proxies for need and social position and the use of healthcare were analysed in the study.

[1] WHO, https://www.who.int/choice/country/country_specific/en/ accessed on Friday, $11^{\text {th }}$ October 2019, 9:08 am.

\section{Results}

\section{Characteristics of the respondents}

Of the 1,899 respondents, $51 \%$ were women and $49 \%$ were men. About $62 \%$ of the respondents were still engaging in economic activities, and $92 \%$ were engaging in subsistence agricultural activities. Most of the old women engaged in small business compared to men. In rural areas, most of the elderly use firewood (74.6\%) as a source of energy.

Table 1. Summary of demographic and socio-economic characteristics of the respondents: frequency (percentages) $(N=1,899)$ 


\begin{tabular}{|c|c|c|c|}
\hline & Female & Male & Total \\
\hline \multicolumn{4}{|l|}{ Age group } \\
\hline $60-69$ & 594(61.3) & $517(55.59)$ & $1111(58.5)$ \\
\hline $70-79$ & $242(24.97)$ & 264(28.39) & $506(26.65)$ \\
\hline $80-89$ & 116(11.97) & 113(12.15) & 229(12.12) \\
\hline $90+$ & $17(1.8)$ & $36(3.9)$ & $53(2.8)$ \\
\hline Total & $969(51.03)$ & $930(48.97)$ & 1899 \\
\hline \multicolumn{4}{|l|}{ Marital status } \\
\hline Married & 279(28.79) & $569(61.18)$ & $848(44.66)$ \\
\hline Not married & $690(71.21)$ & $361(38.82)$ & $1051(55.34)$ \\
\hline Total & 969 & 930 & 2899 \\
\hline \multicolumn{4}{|c|}{ Formal education } \\
\hline No & 654(67.49) & $473(50.86)$ & $1127(59.35)$ \\
\hline Yes & $315(32.51)$ & $457(49.14)$ & 772(40.65) \\
\hline Total & 969 & 930 & 1899 \\
\hline \multicolumn{4}{|l|}{ Education level } \\
\hline No & $654(67.49 \%)$ & $473(50.81 \%)$ & $1,127(59.35)$ \\
\hline Low & 158(50.32) & 204(44.54) & $362(46.89)$ \\
\hline Middle & 138(43.95) & 219(47.82) & $357(46.24)$ \\
\hline High & 18(5.73) & $35(7.64)$ & $53(6.87)$ \\
\hline Total & 969 & 930 & 1899 \\
\hline \multicolumn{4}{|l|}{ Residence } \\
\hline Rural & $502(51.8)$ & $451(48.5)$ & $953(50.2)$ \\
\hline Urban & $467(48.2)$ & $479(51.5)$ & $946(49.8)$ \\
\hline Total & 969 & 930 & 1899 \\
\hline \multicolumn{4}{|c|}{ Currently working } \\
\hline No & $411(42.41)$ & $311(33.44)$ & 722(38.02) \\
\hline Yes & $558(57.59)$ & $619(66.56)$ & $1,177(61.98)$ \\
\hline Total & 969 & 630 & 1899 \\
\hline
\end{tabular}




\begin{tabular}{|c|c|c|c|}
\hline \multicolumn{4}{|l|}{ Type of job } \\
\hline No & $411(42.41)$ & $311(33.44)$ & 722(38.02) \\
\hline Business & $40(7.17)$ & $34(5.49)$ & $74(6.29)$ \\
\hline Casual worker & $7(1.25)$ & $2(0.32)$ & $9(0.76)$ \\
\hline Employed & $1(0.18)$ & $2(0.32)$ & $3(0.25)$ \\
\hline Farming & $510(91.40)$ & $581(93.86)$ & $1091(92.69)$ \\
\hline Total & 969 & 930 & 1899 \\
\hline \multicolumn{4}{|l|}{ Financial provider in your family } \\
\hline Myself & $531(54.80)$ & $647(69.57)$ & $1178(62.03)$ \\
\hline Husband/wife & $99(10.22)$ & $39(4.19)$ & 138(7.27) \\
\hline Children & $303(31.27)$ & $216(23.23)$ & $519(27.33)$ \\
\hline Relatives/others & $36(3.72)$ & $28(3.01)$ & $64(3.37)$ \\
\hline Total & 969 & 930 & 1899 \\
\hline \multicolumn{4}{|l|}{ Type of cooking fuel } \\
\hline Electricity & $2(0.21)$ & $7(0.75)$ & $9(0.47)$ \\
\hline LPG (Gas) & $9(0.93)$ & 11(1.18) & $20(1.05)$ \\
\hline Kerosene & 19(1.96) & $6(0.65)$ & $20(1.05)$ \\
\hline Charcoal & $171(17.65)$ & $170(18.28)$ & $341(17.96)$ \\
\hline Firewood & $721(74.41)$ & $696(74.84)$ & $1417(74.62)$ \\
\hline Dung/others & $47(4.85)$ & $40(4.30)$ & $87(4.59)$ \\
\hline Total & 969 & 930 & 1899 \\
\hline \multicolumn{4}{|l|}{ Source of drinking water } \\
\hline Piped water around the house & $61(6.29)$ & $86(9.25)$ & 147(7.74) \\
\hline Public tap & $258(26.63)$ & $222(23.87)$ & $480(25.28)$ \\
\hline Water from well or borehole & $648(66.88)$ & $610(65.59)$ & $1258(66.24)$ \\
\hline Others & $2(0.20)$ & $12(1.29)$ & $14(0.74)$ \\
\hline Total & 969 & 930 & 1899 \\
\hline \multicolumn{4}{|l|}{ Socio-economic status } \\
\hline Low (q1) & $721(74)$ & $696(75)$ & $1417(75)$ \\
\hline
\end{tabular}




\begin{tabular}{|llll|} 
Middle (q2) & $46(5)$ & $39(4)$ & $85(4)$ \\
\hline High (q3) & $202(21)$ & $195(21)$ & $397(21)$ \\
\hline Total & 969 & 930 & $1899(100)$ \\
\hline
\end{tabular}

Table 2 shows that $43.71 \%$ of the outpatient respondents paid cash directly for the service, and most of them paid themselves (47.99\%). Among 744 respondents who attended the inpatient department, $64.78 \%$ paid cash directly for the services provided. Most of the respondents attended public health facilities $(74.73 \%)$, while the rest attended private and charity or non-government organizations health facilities. Some respondents did not attend health facilities due to different reasons, including financial problems (37.95\%).

Table 2. Summary of the respondents attended at a health facility: frequency (percentages) $(N=1,899)$ 


\begin{tabular}{|c|c|c|c|}
\hline Variables & Female & Male & Total \\
\hline \multicolumn{4}{|c|}{ Did you pay for outpatient? } \\
\hline Yes & $412(42.52)$ & $418(44.95)$ & $830(43.71)$ \\
\hline No & $522(53.87)$ & $482(51.83)$ & 1004(52.87) \\
\hline Don't know & $35(3.61)$ & $30(3.23)$ & $65(3.42)$ \\
\hline \multicolumn{4}{|l|}{ Who paid for outpatient? } \\
\hline Myself & 165(38.92) & $240(54.14)$ & 405(47.99) \\
\hline My wife/husband & $27(6.37)$ & $11(2.62)$ & $38(4.50)$ \\
\hline My child/children & 178(41.98) & $129(30.71)$ & $307(36.37)$ \\
\hline My relatives/others & $54(12.74)$ & $40(9.53)$ & $94(11.14)$ \\
\hline \multicolumn{4}{|c|}{ Did you pay for inpatient? } \\
\hline Yes & $246(62.44)$ & $236(67.43)$ & $482(64.78)$ \\
\hline No & 148(37.56) & 114(32.57) & 262(35.22) \\
\hline \multicolumn{4}{|l|}{ Who paid for inpatient? } \\
\hline Myself & $65(21.24)$ & $91(30.33)$ & 156(25.74) \\
\hline Wife/husband & $7(2.29)$ & $8(2.67)$ & $15(2.48)$ \\
\hline Children & 146(47.71) & $132(44)$ & $278(45.87)$ \\
\hline Non-family members & $31(10.13)$ & $26(8.67)$ & $57(9.41)$ \\
\hline Insurance & 28(9.15) & $26(8.67)$ & $54(8.91)$ \\
\hline Service was free & $29(9.48)$ & $17(5.67)$ & 46(7.59) \\
\hline \multicolumn{4}{|c|}{ In the last 12 months, have you ever stayed overnight in a hospital? (bed day) } \\
\hline No & $584(60.27)$ & $571(64.40)$ & $1155(60.82)$ \\
\hline Yes & $385(39.73)$ & $359(38.60)$ & $744(39.18)$ \\
\hline \multicolumn{4}{|c|}{$\begin{array}{l}\text { In the last } 12 \text { months, how many different times were you a patient in a hospital for at least one } \\
\text { night? }\end{array}$} \\
\hline Once & $24(62.60)$ & $241(67.13)$ & $482(64.78)$ \\
\hline Twice & $91(23.64)$ & $76(21.17)$ & $167(22.45)$ \\
\hline Three times & $39(10.13)$ & $18(5.01)$ & $57(7.66)$ \\
\hline More than three times & $14(3.64)$ & $24(6.69)$ & $38(5.11)$ \\
\hline
\end{tabular}




\begin{tabular}{|lccc|}
\hline Public & $289(75.06)$ & $267(74.37)$ & $556(74.73)$ \\
\hline Private & $64(16.62)$ & $67(18.66)$ & $131(17.61)$ \\
\hline Charity/NGOs & $31(8.05)$ & $22(6.13)$ & $53(7.12)$ \\
\hline I don't know & $1(0.26)$ & $3(0.84)$ & $4(0.54)$ \\
\hline Have you (last 12 months) believed yourself to need hospitalisation but refrained from seeking care? \\
\hline Yes & $409(42.21)$ & $372(40.00)$ & $781(41.13)$ \\
\hline No & $560(57.79)$ & $558(60.00)$ & $1,119(58.87)$ \\
\hline What was/were the reason(s) why you did not seek medical care (more than one answer)? & $118(27.00)$ & $100(24.94)$ & $218(26.01)$ \\
\hline Problem cleared up & $174(39.82)$ & $144(35.95)$ & $318(37.95)$ \\
\hline Financial problems & $145(33.18)$ & $157(39.15)$ & $302(36.04)$ \\
\hline Other reasons & & &
\end{tabular}

Table 3 indicates the relationship between the mean cost for both outpatient and inpatient care and EQ$5 \mathrm{D}$ scores. Results indicate that as EQ-5D scores increase, the cost for both inpatient and outpatient care decreases. This means that people with low QoL have higher costs for both outpatient and inpatient care compared to those with high QoL.

Table 3. Summary of average expenditures on access to outpatient and inpatient healthcare use and outof-pocket (OOP) payment $(N=1,899)$ 


\begin{tabular}{|lllllll|}
\hline EQ-5D Index & $\begin{array}{l}\text { Number } \\
\text { of } \\
\text { people }\end{array}$ & $\begin{array}{l}\text { Mean cost } \\
\text { outpatient } \\
\mathbf{( \$ )}\end{array}$ & $\begin{array}{l}\text { Number } \\
\text { of } \\
\text { people }\end{array}$ & $\begin{array}{l}\text { Mean cost } \\
\text { inpatient } \\
\mathbf{( \$ )}\end{array}$ & $\begin{array}{l}\text { Mean OOP } \\
\text { inpatient } \mathbf{( \$ )}\end{array}$ & $\begin{array}{l}\text { Mean OOP } \\
\text { outpatient } \\
\mathbf{( \$ )}\end{array}$ \\
\hline$<=\mathbf{0 . 1 0 9}$ & 10 & 14.08 & 8 & 37.9 & 9.47 & 11.68 \\
\hline $\mathbf{0 . 1 1 0 - 0 . 2 0 9}$ & 6 & 65.53 & 6 & 83.71 & 10.76 & 6.19 \\
\hline $\mathbf{0 . 2 1 0 - 0 . 3 0 9}$ & 18 & 13.32 & 14 & 75.63 & 10.27 & 6.38 \\
\hline $\mathbf{0 . 3 1 0 - 0 . 4 0 9}$ & 14 & 13.09 & 12 & 23.3 & 2.85 & 6.30 \\
\hline $\mathbf{0 . 4 1 0 - 0 . 5 0 9}$ & 27 & 9.29 & 17 & 40.78 & 3.30 & 7.33 \\
\hline $\mathbf{0 . 5 1 0 - 0 . 6 0 9}$ & 285 & 10.46 & 208 & 36.03 & 4.97 & 6.56 \\
\hline $\mathbf{0 . 6 1 0 - 0 . 7 0 9}$ & 131 & 8.68 & 94 & 30.29 & 3.80 & 6.18 \\
\hline $\mathbf{0 . 7 1 0 - 0 . 8 0 9}$ & 245 & 9.82 & 173 & 32.61 & 3.72 & 6.20 \\
\hline $\mathbf{0 . 8 1 0 - 0 . 9 0 9}$ & 107 & 10.49 & 69 & 34.65 & 2.21 & 6.44 \\
\hline $\mathbf{0 . 9 1 0 - 1 . 0 0}$ & 222 & 7.92 & 143 & 40.3 & 4.04 & 6.93 \\
\hline Total & 1065 & & 744 & & & \\
\hline
\end{tabular}

Key: Mean OOP=mean of out-of-pocket payment (lab test, medicines, and registration cost); Mean cost=mean of healthcare use (lab test, medicines, registration fees, cost per visit, bed day cost, and transport cost)

In Graph 1, the OOP payments have been added, which indicates the relationship between the mean cost of outpatient and inpatient care with the QoL - i.e., the elderly with poor health use much more healthcare (outpatient and inpatient) compared to those with good health. The difference between the total HE and OOP payments in this study is that OOP payments include only the amount paid by the elderly at the health facility, while the total HE includes OOP payments and other costs like transport cost, costs per visit, and bed day costs. In short, OOP payments are the direct payments that were paid by the elderly at the health facility.

Table 4. The relationship between SES and mean cost for both outpatient and inpatient care 


\begin{tabular}{|cllllll|}
\hline $\begin{array}{l}\text { Socio- } \\
\text { economic } \\
\text { status }\end{array}$ & $\begin{array}{l}\text { Number } \\
\text { of } \\
\text { people }\end{array}$ & $\begin{array}{l}\text { Mean cost } \\
\text { of } \\
\text { outpatient } \\
\text { care }\end{array}$ & $\begin{array}{l}\text { Number } \\
\text { of } \\
\text { people }\end{array}$ & $\begin{array}{l}\text { Mean cost } \\
\text { of inpatient } \\
\text { care }\end{array}$ & $\begin{array}{l}\text { Mean OOP cost } \\
\text { for outpatient } \\
\text { care }\end{array}$ & $\begin{array}{l}\text { Mean 0OP } \\
\text { cost for } \\
\text { inpatient care }\end{array}$ \\
\hline $\begin{array}{c}\text { Low } \\
\text { (q1) }\end{array}$ & 782 & 9.98 & 565 & 37.43 & 6.29 & 4.26 \\
$\begin{array}{c}\text { Middle } \\
\text { (q2) }\end{array}$ & 56 & 15.83 & 35 & 32.49 & 10.20 & 3.93 \\
$\begin{array}{c}\text { High } \\
(\mathrm{q} 3)\end{array}$ & 227 & 8.46 & 144 & 32.54 & 6.62 & 3.44 \\
\hline & 1065 & 744 & & & \\
\hline
\end{tabular}

Table 4 indicates that the elderly have almost the same healthcare cost regardless of their social position (low, middle, and high quartile).

In addition, there is a low mean for the OOP payments compared to the cost for the healthcare use for both outpatient and inpatient care, as indicated in Graph 1.

\section{Regression analysis}

Three simple linear regression analyses were performed to assess the factors associated with $\mathrm{HE}$, which represent the cost of accessing outpatient and inpatient healthcare among the elderly.

Table 5. Linear regression analysis for both outpatient and inpatient care 
Model 1

$\mathrm{HE}(\mathrm{OP})=\mathrm{QoL}+\mathrm{Age}$

Coef $\quad \mathrm{P}>|\mathrm{t}| \quad 95 \% \mathrm{Cl}$ $-9.406$

QoL Age

60-69 0

70-79

$-0.801$

$0.510 \quad-3.184$

$1.582 \quad 1.533$

0.720

$-6.857 \quad 9.922$

80-89

3.187

$0.045 \quad 0.071$

$6.303 \quad 13.803$

$0.159-1.719$

4.398

$90+$

$\mathrm{HE}(\mathrm{OP})=\mathrm{SES}+$ Age

SES

Low (q1) 0

Middle (q2)

High (q3)

5.812

$0.011 \quad 1.308$

$10.315 \quad-6.208$

0.486

$-23.673 \quad 11.258$

$\begin{array}{lllll}-1.438 & 0.252 & -3.898 & 1.022 & -3.987\end{array}$

0.379

$-12.880 \quad 4.906$

Age

60-69 0

$70-79$

$-0.558$

$0.647 \quad-2.946$

1.830

2.155

0.615

$-6.242$

10.551

80-89

3.839

$0.015 \quad 0.737$

$6.942 \quad 15.291$

0.008

$3.940 \quad 26.641$

$90+$

5.582

$0.072 \quad-0.507$

$11.671-5.244$

0.640

$-27.242 \quad 16.753$

HE

$(\mathrm{OP})=\mathrm{Q} o \mathrm{~L}+\mathrm{SES}+\mathrm{Age}$

HE (IP $)=Q \circ L+S E S+A g e$

QoL

$-9.707$

$0.000 \quad-14.851$

$-4.564 \quad-26.851$

0.006

$-45.961$

$-7.740$

SES

Low (q1) $\quad 0$

Middle (q2)

6.358

$0.006 \quad 1.871$

$10.844 \quad-4.995$

0.575

$-22.452 \quad 12.462$

High (q3)

$-1.173$

$0.347 \quad-3.623$

$1.276-3.646$

0.421

$-12.527$

5.235

Age

\begin{tabular}{ll}
$60-69$ & 0 \\
\hline $70-79$ & -0.80 \\
$80-89$ & 3.
\end{tabular}

$-0.808$

$\begin{array}{lll}3.155 & 0.046 & 0.049\end{array}$

6.260

1.366

0.750

$-7.035$

9.767

Page 14/21 
Key: OP=outpatient care; $I P=$ inpatient care

Table 5 presents three simple linear regression analyses. Models 1 and 2 represent the relationship between HE for outpatient and inpatient care, respectively, with the independent variables of QoL, SES, and age. In these three linear regression analyses, we found an association between HE for both outpatient and inpatient care and QoL, which is statistically significant. This means that HE for outpatient and inpatient care increases with the decrease of QoL. For age, although it seems only one group was statistically significant in all three linear regression analyses, it indicates that as age increases, the HE for outpatient and inpatient care increases. SES of the elderly only in the middle group was statistically significant to explain the HE for outpatient care, while it had no influence on the HE for inpatient care, since the mean cost for inpatient care had almost the same values in all groups.

\section{Discussion}

This study analysed the association among health status (QoL), health cost (HE), and social position (SES) among the elderly in Igunga and Nzega districts. The main findings of this study indicate an association between poor health of the elderly (low QoL) and high costs for healthcare and no association between social position (SES) and health costs for healthcare among the elderly. This means that the elderly with poor health use more healthcare compared to those with good health, regardless of their social position. Similar findings were reported in India and elsewhere (25-27) that the elderly with chronic diseases and poor health reduced their health status, which, in turn, leads to an increase of HE.

As was expected, the study found an association between age and HE. This is because as age increases, the health status of the elderly starts to deteriorate, with a decrease of QoL, which, in return, increases the $\mathrm{HE}$ among the elderly to improve their health status. The findings concur with previous studies done in Tanzania and elsewhere $(16,19,28-30)$, which revealed that as age increases, the health status of the elderly decreases and the HE increases.

In LMICs, most of the elderly suffer from catastrophic HEs due to not being well defined in the financing healthcare service system and other policies, including the exemption policy for the elderly. However, the study found that health spending does not depend on the level of SES of the individual. These findings concur with other studies done in China, Burkina Faso, and some countries in Asia (31-33). The influence of social position could be clearer in the long term than in the short term. In the short term, when the elderly are ill, they need treatment, and after receiving the treatment they can improve their health status whether they are poor or rich. In the long term, both QoL and HE are influenced by the level of social position (SES).

\section{Policy Implications}


There have been many efforts to improve healthcare services to all Tanzanians, which are well established in different documents, including the Tanzania Development Vision 2025 (TDV 2025), the National Health Policy 2017, the National Five Year Development Plan 2016/17 - 2020/21, the Sustainable Development Goals 2030, and the Health Sector Strategic Plan 2015 - 2020 (34). However, there are still many challenges facing the elderly in accessing free or almost free healthcare services. Due to these challenges, local government authorities (LGAs) are obliged to handle the priority setting process in a way that can benefit vulnerable groups like the elderly. This can be done by LGAs using the bottomup decision-making system, whereby the priority setting process starts from the lower level by reorganising the problems around individuals and proposes good measures. The government, especially LGAs, when setting their priorities should consider the interdependence of health, wealth, and HE to improve the health among the elderly. This can be done by increasing the budget for the elderly through subsidising the healthcare services of the elderly. To help the elderly, the government can also establish health insurance (risk pooling) specifically for vulnerable groups, including the elderly. This will help to reduce the challenges of exemption policy in accessing health services among the elderly.

\section{Strengths And Limitations}

The strength of this study lies in the fact that it provides information on the association among health (QoL), social position (SES), HE, and age among the elderly, which may contribute to the priority setting during planning for the resource allocation to the vulnerable groups, including the elderly especially at the LGAs in rural Tanzania. The study used cross-sectional data, which may not capture the causality of the problems facing the elderly in financing the healthcare services to reduce the burden of diseases. This may be one of the limitations of the study. Another limitation is self-reported data that might have created recall bias and heterogeneity among the elderly on socio-economic factors (monthly income/wealth) and self-rated health data. Recall bias might influence the validity and reliability of the study findings. These problems were minimised by conducting a pilot test of the survey tool, which helped to refine some of the questions. During interviews, questions were elaborated to the respondents.

\section{Conclusion}

The health system in these districts allocates resources mainly according to needs, and social position does not influence them. A relatively small proportion of the total costs for healthcare is financed by OOP payments. We thus conclude that the system is reasonably fair. Health, not wealth, determines the use of medical expenditures.

\section{Declarations}

\section{Ethical Considerations}

While conducting this study, all respondents were given a full explanation about the aims of the study and their rights to participate in the study without any condition. The study was approved by the ethics 
committee of the Muhimbili University of Health and Allied Sciences (Decision No. 2017-05-

24/AEC/Vol.XI//70). Permission for ground data collection was obtained from the District Executive Directors of the Igunga and Nzega districts. Before the survey, individual written consent was obtained from the participants, while verbal consent was obtained from the participants who could not read and write. All the participants were fully informed about the research and their rights to participate or withdraw from the study.

\section{Acknowledgements}

We wish to acknowledge the people of the Igunga and Nzega districts for agreeing to participate in the study. Also, we thank Sida for their support, the MUHAS Research Board, the Regional Administrative Secretary of Tabora region, and the District Executive Directors of Igunga and Nzega districts.

\section{Author contributions}

MT and PJA participated in data collection. MT participated in its design, analysed data and drafted the manuscript. LL, MM, PGM, PJA, and ADK participated in the design, analysis and helped to draft the manuscript. All the authors read and approved the final manuscript.

\section{Declaration of Conflicting Interests}

The author(s) declare no potential conflicts of interest concerning the research, authorship, and/or publication of this article.

\section{Funding}

Sida fully supported this study financially for the research, authorship, and/or publication of this article.

\section{References}

1. Rudawska I. Epidemiologic and demographic trends as a challenge for European health care systems. Probl Zarz [Internet]. 2013;11(41):34-52. Available from: http://pz.wz.uw.edu.pl/sites/default/files/artykuly/pz_1-2_2013_rudawska.pdf

2. Brinda EM, Rajkumar AP, Enemark U, Prince M JK. Nature and correlates of out of pocket health expenditure among elderly in a rural south Indian community. 2012;

3. Kinsella K, Phillips D, Butz WP, Bentzen MP, Hokenson RF. Global Aging: The Challenge of Success Population Reference Bulletin. Popul Bull [Internet]. 2005;60(1). Available from: http://www.prb.org/pdf05/60.1globalaging.pdf

4. The united republic of Tanzania ministry of health and social welfare. The United Republic of Tanzania: Ministry of Health and Social Welfare, PRIMARY HEALTH SERVICES DEVELOPMENT PROGRAMME- MMAM 2007 - 2017. 2007;(1):2013. 
5. Bergmark $\AA$, Parker MG, Thorslund M. Priorities in care and services for elderly people: a path without guidelines? J Med Ethics. 2000;26:312-8.

6. Maluka S, Kamuzora P, Sebasti??n MS, Byskov J, Olsen ??ystein E., Shayo E, et al. Decentralized health care priority-setting in Tanzania: Evaluating against the accountability for reasonableness framework. Soc Sci Med [Internet]. 2010;71(4):751-9. Available from:

http://dx.doi.org/10.1016/j.socscimed.2010.04.035

7. World Health Organisation. Global Health Ethics: Key Issues. Glob Netw WHO Collab Centres Bioeth [Internet]. 2015;32. Available from:

http://apps.who.int/iris/bitstream/10665/164576/1/9789240694033_eng.pdf

8. Hauck K, Smith PC, Goddard M. The Economics of Priority Setting for Health Care: A Literature Review. 2004;(September):92.

9. Coast J, Smith RD, Lorgelly P. Welfarism, extra-welfarism and capability: The spread of ideas in health economics. Soc Sci Med. 2008;67(7):1190-8.

10. Adisa O. Investigating determinants of catastrophic health spending among poorly insured elderly households in urban Nigeria. Int J Equity Health [Internet]. 2015;14(1):79. Available from: http://www.scopus.com/inward/record.url?eid=2-s2.0-84941647513\&partnerlD=tZOtx3y1

11. ABDU IC. CHALLENGES OF GOVERNMENT HEALTH SERVICES TO ELDERLY PEOPLE IN TANZANIA: THE CASE OF KINONDONI AND ILALA DISTRICT COUNCILS. Open Univ Tanzania [Internet]. 2018;A

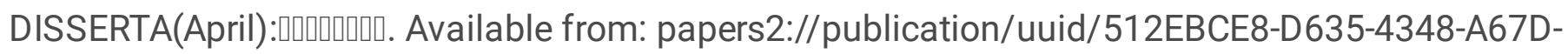
22DD52988F4C

12. Ministry of Labour Youth Development and Sports. United Republic of Tanzania: National Ageing Policy 2003. 2003;1-18. Available from:

http://www.globalaging.org/elderrights/world/2007/BGTanzania.pdf

13. Li Y, Wu Q, Xu L, Legge D, Hao Y, Gao L, et al. Factors affecting catastrophic health expenditure and impoverishment from medical expenses in China: policy implications of universal health insurance. Bull World Health Organ [Internet]. 2012;90(9):664-71. Available from:

http://www.who.int/bulletin/volumes/90/9/12-102178.pdf

14. McHenga M, Chirwa GC, Chiwaula LS. Impoverishing effects of catastrophic health expenditures in Malawi. Int J Equity Health [Internet]. 2017;16(1):1-8. Available from: http://dx.doi.org/10.1186/s12939017-0515-0

15. WHO (World Health Organization). Health Systems Strengthening: Glossary. 2012;1-22. Available from: http://www.who.int/healthsystems/hss_glossary/en/index.html 
16. Tungu M, Amani PJ, Hurtig AK, Dennis Kiwara A, Mwangu M, Lindholm L, et al. Does health insurance contribute to improved utilization of health care services for the elderly in rural Tanzania? A crosssectional study. Glob Health Action [Internet]. 2020;13(1). Available from: https://doi.org/10.1080/16549716.2020.1841962

17. Malalika B, Submitted D, Policy P. IMPLEMENTATION OF THE NATIONAL AGEING POLICY IN TANZANIA: WHAT DO STREET LEVEL BUREAUCRATS AND CLIENTS SAY ABOUT ACCESS TO FREE HEALTH SERVICES BY THE ELDERLY POPULATION IN MOROGORO MUNICIPALITY? 2016;

18. Mubyazi GM. The Tanzanian policy on health-care fee waivers and exemptions in practice as compared with other developing countries: evidence from recent local studies and international literature. East Afr J Public Health [Internet]. 2004;1(1):11-7. Available from: http://www.bioline.org.br

19. Tungu M, Frumence G, Mwangu M, Hurtig AK, Lindholm L. Can survey data facilitate local priority setting? Experience from the Igunga and Nzega districts in Tanzania. Qual Life Res [Internet]. 2020; Available from: https://doi.org/10.1007/s11136-020-02547-w

20. Mwanyangala M, Mayombana C, Urassa H, Charles J, Mahutanga $\mathrm{C}$, Abdullah S, et al. Health status and quality of life among older adults in rural Tanzania. Glob Health Action [Internet]. 2010;3(1):2142. Available from: https://www.tandfonline.com/doi/full/10.3402/gha.v3i0.2142

21. Saif-Ur-Rahman KM, Anwar I, Hasan M, Hossain S, Shafique S, Haseen F, et al. Use of indices to measure socio-economic status (SES) in South-Asian urban health studies: a scoping review. Syst Rev. 2018;7(1):196.

22. National Bureau of Statistics (NBS). Tanzania in figures 2016. Natl Bur Stat Dar es Salaam, Tanzania. 2017;

23. Altman DG. PRACTICAL STATISTICS FOR MEDICAL The Analysis of Time Series. 1997.

24. You X, Kobayashi Y. Determinants of out-of-pocket health expenditure in China: analysis using China Health and Nutrition Survey data. Appl Health Econ Health Policy. 2011;9(1):39-49.

25. Loutfi D, Lévesque J. Impact of the Elderly on Household Health Expenditure in Bihar and Kerala, India. 2018;

26. de Meijer C, Wouterse B, Polder J, Koopmanschap M. The effect of population aging on health expenditure growth: A critical review. Eur J Ageing. 2013;10(4):353-61.

27. Lubitz J, Cai L, Kramarow E, Lentzner H. Health, life expectancy, and health care spending among the elderly. N Engl J Med. 2003;349(11):1048-55.

28. Phaswana-Mafuya N, Peltzer K, Chirinda W, Kose Z, Hoosain E, Ramlagan S, et al. Self-rated health and associated factors among older South Africans: Evidence from the study on global ageing and adult 
health. Glob Health Action. 2013;6(1).

29. Mwanyangala M a, Mayombana $\mathrm{C}$, Urassa $\mathrm{H}$, Charles J, Mahutanga $\mathrm{C}$, Abdullah $\mathrm{S}$, et al. Health status and quality of life among older adults in rural Tanzania. Glob Health Action. 2010;3(2):36-44.

30. Wandera SO, Golaz V, Kwagala B, Ntozi J. Factors associated with self-reported ill health among older Ugandans: A cross sectional study. Arch Gerontol Geriatr [Internet]. 2015;61(2):231-9. Available from: http://dx.doi.org/10.1016/j.archger.2015.05.006

31. Su TT, Kouyaté B, Flessa S. Catastrophic household expenditure for health care in a low- income society: a study from Nouna District, Burkina Faso. 2006;023739(05):21-7.

32. Flores G, Krishnakumar J, Doorslaer EVAN. COPING WITH HEALTH-CARE COSTS: IMPLICATIONS FOR THE MEASUREMENT OF CATASTROPHIC EXPENDITURES. 2008;1412(February):1393-412.

33. Li Y, Wu Q, Liu C, Kang Z, Xie X, Yin H, et al. Catastrophic health expenditure and rural household impoverishment in China: What role does the new cooperative health insurance scheme play? PLoS One. 2014;9(4).

34. MHCDGEC. The United Republic of Tanzani: The National Health Policy 2017. 2017;(October):1-65.

\section{Figures}

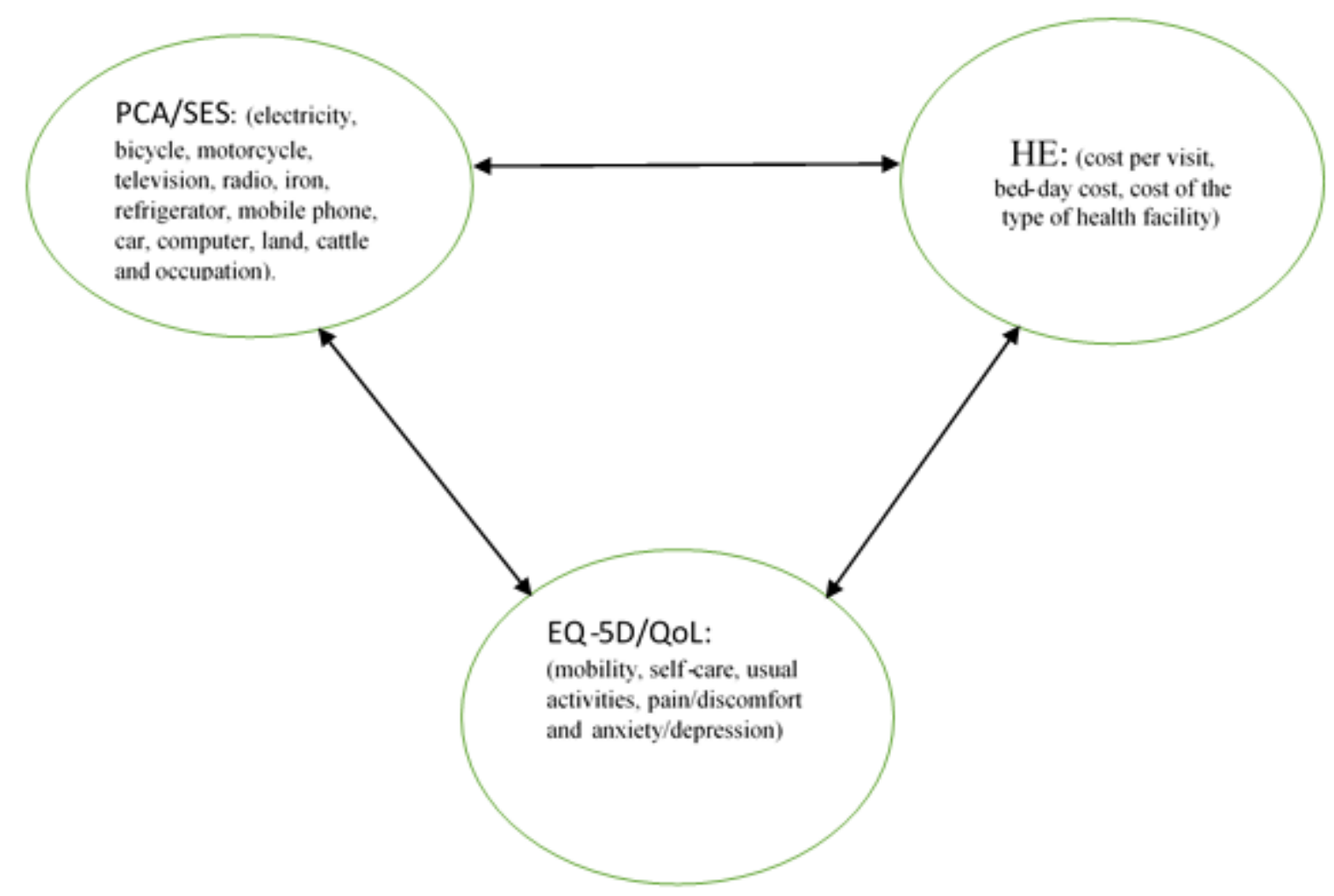

Figure 1 
The relationship among healthcare use, QALYS, and SES

\section{Supplementary Files}

This is a list of supplementary files associated with this preprint. Click to download.

- Graph1.png

- Graph2.png 